\title{
Super-Pnicogen Bonding in the Radical Anion of the Fluorophosphine Dimer
}

\author{
Dani Setiawan ${ }^{\mathrm{a}}$, Dieter Cremer ${ }^{\mathrm{a}, *}$ \\ ${ }^{a}$ Computational and Theoretical Chemistry Group (CATCO), Department of Chemistry, Southern Methodist University, 3215 Daniel Ave, \\ Dallas, Texas 75275-0314, USA
}

\begin{abstract}
The LUMO of the pnicogen-bonded fluoro-phosphine dimer has PP bonding character. Radical anion and dianion form relatively strong pnicogen bonds with some covalent character where however the dianion turns out to be a second order transition state. The binding energy of (FPH2) ${ }_{2}^{-}$is $30.4 \mathrm{kcal} / \mathrm{mol}$ (CCSD(T)/aug-cc-pVTZ; CASPT2(5,8): 30.7 $\mathrm{kcal} / \mathrm{mol}$ ) and the bond strength order measured with the local PP bond stretching force constant increases from 0.055 for the neutral dimer to 0.187 thus revealing that the stabilization of the radical anion is to a large extend a result of one-electron six-center delocalization. Pnicogen-bonded complexes have a stabilizing electron affinity.
\end{abstract}

\section{Introduction}

The existence of pnicogen bonding between phosphines carrying an electronegative substituent $\mathrm{X}$ such as $\mathrm{X}=\mathrm{F}$, $\mathrm{CN}$, etc. is a well-established fact and has been documented in literally dozens of research paper only few can be mentioned here.[1, 2, 3, 4, 5, 6, 7] As in the case of $\mathrm{H}$ bonding, pnicogen bonding is partly covalent and partly electrostatic. [5] The covalent part involves a charge transfer from the $\mathrm{P}$ lone pair orbital into the $\sigma^{\star}(P X)$ orbital. The covalent contribution is substantial if $\mathrm{X}$ has a larger electronegativity than $\mathrm{P}$ so that the $\sigma^{\star}(P X)$ orbital is lowlying and has a large coefficient at $\mathrm{P}$ thus increasing the overlap between lone pair and $\sigma^{\star}(P X)$ orbital.[4, 5, 6] The electrostatic contribution depends on the polarizability of the interacting phosphines, which is largely determined by that of substituent X. Use of the Cremer-Kraka criterion for covalent bonding helps to quantify the covalent and the electrostatic contributions to pnicogen bonding. [5, 8, 9, 10]

We have recently introduced a quantitative scale for determining the strength of pnicogen bonding, [4, 5] which is exclusively based on vibrational spectroscopy and involves a six-step procedure: i) The $3 \mathrm{~N}-\mathrm{L}$ (N: number of atoms in the complex; L: degrees of translation and rotation) vibrational frequencies are determined using either experiment or computations. ii) The vibrational frequencies are used to determine local mode frequencies associated with a specific internal coordinate. $[11,12,13]$ iii) Since frequencies are mass-dependent, they are replaced by the local force constants, $[11,13,4,5]$ which directly reflect features of the electronic structure of a complex. iv) The local PP stretching force constants are used to determine a PP bond strength order (BSO) based on suitable reference bonds. v) The degree of covalent character of a given pnicogen bond is characterized by the energy density at the critical

* Corresponding author point $\mathbf{r}_{b}$ between the $\mathrm{P}$ atoms. $[5,8,9,10]$ vi) Comparison of binding energies and BSO values in form of a correlation diagram reveals whether the stability of the complex is exclusively due to pnicogen bonding or includes also electrostatic attraction, dispersion interactions, etc. between other parts of the monomers. [5]

Following this strategy, it was found that $\left(\mathrm{PH}_{2} \mathrm{~F}\right)_{2}(\mathbf{1})$ has by far the strongest pnicogen bond (BSO value: $n$ $=0.082$ compared to $\mathrm{n}\left(\left(\mathrm{PH}_{3}\right)_{2}\right)=0.017$; CASPT2 calculations). In general, weak pnicogen bonding in alkylsubstituted phosphines can be increased by electrostatic interactions caused by easily polarizable substituents, the inclusion of pseudo- $\pi$ or $\pi$-orbitals if phosphines of the type $\mathrm{PX}_{3}$ (e.g., $\mathrm{X}=\mathrm{Br}$ or $\mathrm{CN}$ ) are involved, or the presence of strongly electronegative substituents $\mathrm{X}$ that lead to a lowlying $\sigma^{\star}(P X)$ orbital. Binding energies $\Delta E$, which include all interactions between the monomers can increase up to $10.1 \mathrm{kcal} / \mathrm{mol}$ if polarizable groups are contained in the pnicogen-bonded complex (e.g., $\left.\mathrm{H}_{3} \mathrm{~N} \cdots \mathrm{P}(\mathrm{CN})_{3}[5]\right)$. In this work, we will report on an even stronger pnicogenbonded complex that is based on a new type of pnicogen bonding.

When investigating pnicogen-bonding in dimer $\left(\mathrm{PH}_{2} \mathrm{~F}\right)_{2}$ (1), we realized that both the HOMO and LUMO have some P,P bonding character as shown in Figure 1. This caused us to study pnicogen bonding in the case of a radical anion or dianion of dimer $\mathbf{1}$ (2 and $\mathbf{3}$ ) for the purpose of finding out whether these complexes are thermodynamically and/or kinetically stable. To relate the properties of these complexes to those molecules with known PP bonding, also the radical cation $\mathbf{4}$, the dication $\mathbf{5}$, the (un)charged) monomers $\mathbf{7}$ - 10, diphosphane (11), and diphosphene (12; see Figure 2) were investigated. Especially, $\mathbf{4}$ and $\mathbf{5}$ were of interest as these should no longer be destabilized by lone-pair, lone-pair (lp-lp) repulsion as in complex $\mathbf{1}$. The purpose of this study is to demonstrate that strong, largely covalent pnicogen bonds are possible, 
which lead to a new type of pnicogen-bonded complexes.

\section{Computational Methods}

Preliminary calculations of the complex geometries and binding energies were carried out with DFT employing the hybrid functional $\omega \mathrm{B} 97 \mathrm{X}-\mathrm{D},[14,15]$ which includes dispersion effects, and the frozen-core dispersion-corrected double-hybrid XC functional with spin-scaled-MP2, DSDBLYP.[16] The geometries obtained in this way were used as starting geometries for $\operatorname{CCSD}(\mathrm{T})$ (coupled cluster with all single and double excitations and using a perturbative approach for the triple excitations)[17] and CASPT2 (complete-active space self-consistent field calculations with second order perturbation corrections) [18] calculations where for the open-shell complexes a UHF (Unrestricted Hartree Fock) wave function was used (unrestricted Kohn-Sham (UKS) in the case of the DFT calculations). At all levels of theory, Dunning's aug-cc-pVTZ basis set[20, 21] were employed to describe the negatively charged complexes with an appropriate set of diffuse functions.

Complex binding energies $\Delta E$ were obtained by subtracting the energies of the monomeric subunits $\mathbf{6}-10$ in Figure 2 from the dimer energy and correcting $\Delta E$ for basis set superposition errors (BSSE) utilizing the counterpoise method.[22] In the case of the CASPT2 calculations, the binding energy $\Delta E$ was also calculated by stepwise increasing the interaction distance to $15 \AA$ and getting in this way a BSSE-free value, which was compared with the BSSE-corrected $\Delta E$. The active space for the CASPT2 calculations was limited to the molecular orbitals (MOs) 25 to 32 (first entry: monomer 1; second entry: monomer 2) that are important for the pnicogen interactions. Occupied set: MO 25: $\operatorname{lp}(\mathrm{P})+\operatorname{lp}(\mathrm{P}) ; \mathrm{MO} 26$ : $\operatorname{lp}(\mathrm{P})-\operatorname{lp}(\mathrm{P})$; Virtual set: MO27: $\sigma^{\star}(P F)+\sigma^{\star}(P F) ; \mathrm{MO}$ 28: pseudo- $\pi\left(\mathrm{PH}_{2}\right)+$ pseudo- $\pi\left(\mathrm{PH}_{2}\right)$; MO 29: pseudo$\pi\left(P_{2}\right)$ - pseudo- $\pi\left(P_{2}\right) ;$ MO 30: $\sigma^{\star}(P F)-\sigma^{\star}(P F)$; MO 31: $\left[\sigma\left(P H_{2}\right)+\operatorname{lp}(\mathrm{P})\right]+\left[\sigma\left(P H_{2}\right)+\operatorname{lp}(\mathrm{P})\right] ;$ MO 32: $\left[\sigma\left(P H_{2}\right)+\operatorname{lp}(\mathrm{P})\right]-\left[\sigma\left(P H_{2}\right)+\operatorname{lp}(\mathrm{P})\right]$. This leads for $\mathbf{1}, \mathbf{2}$, and 3 to a $(4,8),(5,8)$, and $(6,8)$ active space, respectively, abbreviated in the following as $(\mathrm{N}, 8)$ space. We made also test calculation for the corresponding $(5,12)$ active space for radical anion $\mathbf{2}$, which did not lead to a change in the results and therefore, the $(\mathrm{N}, 8)$ spaces were used throughout the investigation. In the case of the CASPT2 calculations a core correlated aug-cc-pwCVTZ basis set[23] was used because, contrary to $\operatorname{CCSD}(\mathrm{T})$, core electrons were not eliminated from the correlation.

For all complexes investigated, vibrational frequencies were calculated either analytically or numerically (CASPT2) to obtain the local mode properties using the method of Konkoli and Cremer.[11] BSO values $n(P P)$ were derived by using for the $\mathrm{PP}$ bonds in $\mathrm{P}_{2} \mathrm{H}_{4}$ (11) and $\mathrm{P}_{2} \mathrm{H}_{2}$ (12) as suitable reference bonds with Wiberg indices of 0.923 and 1.673 for CCSD(T) and 0.951 and 1.705 for CASPT2, which reflect the fact that for third period elements $\pi$ bonding is reduced. A power relationship of the type
$\left.n(P P)=a\left[k^{a}(P P)\right]^{b}\right]$ with $\mathrm{a}=0.503$ and $b=1.015$ for CASPT2 (0.540, 0.938 for $\operatorname{CCSD}(\mathrm{T}))$ was used to convert local PP stretching force constants into $\mathrm{BSO}(\mathrm{PP})$ values (for $k^{a}=0, n=0$ was enforced). Spin contamination was annihilated at the UDFT level[24] whereas in the case of the UHF-CCSD(T) the first spin contamination is annihilated by the full CI character of CCSD[25] and the second and higher contaminations were small and could be ignored. In all cases, the PP critical points $\mathbf{r}_{b}$ of the electron density distribution were determined and then the Cremer-Kraka criteria were applied to determine the covalent or electrostatic character of the PP-interaction with the help of the energy density distribution at the critical point $\mathbf{r}_{b} \cdot[8,9,10]$ According to these criteria, a negative energy density in the region between interacting atoms indicates stabilization and leads to accumulation of electron density, which is typical of a covalent bond. Noteworthy is that the energy density integrated over the bond region can be used to define a bond energy.[26] The BSO and the local stretching force constant are related to the intrinsic bond dissociation energy, which is the energy that is obtained when freezing the electronic structure of a molecule during the dissociation of a particular bond.[27] Therefore, we use in this work, the BSO as bond strength descriptor and the energy density as descriptor of the covalency of the bond.

Difference density distributions $\Delta \rho(\mathbf{r})=\rho(\mathbf{2}, \mathbf{r})-\rho(\mathbf{1}, \mathbf{r})$ were calculated using the geometry of $\mathbf{2}$ obtained at the CCSD(T) level of theory. The local PP stretching modes and their properties were calculated with the program COLOGNE2016.[28] CASPT2 calculations were carried out with the MOLPRO[29] program package, whereas the CCSD(T) calculations were performed with CFOUR.[30] The electron and energy densities at the bond critical point were analyzed with the AIMAll program[31].

\section{Results and Discussion}

In Table 1, calculated binding energies $\Delta E$ of complexes $\mathbf{1}$ - $\mathbf{5}$ are listed. CASPT2 and CCSD(T) predict for 1 a $\Delta E$ value of 6.5 and $6.4 \mathrm{kcal} / \mathrm{mol}$, respectively, which increases to 30.7 and $30.4 \mathrm{kcal} / \mathrm{mol}$, respectively, for the radical anion $\mathbf{2}$ in line with the fact that that the LUMO of 1 has P,P bonding character (Figure 1). The P,P interaction distance is reduced from $2.618 \AA$ in 1 to $2.514 \AA$ in 2 (CASPT2, Figure 2; CCSD(T): from 2.628 to $2.541 \AA$ ). The dianion has an even shorter PP distance (2.488 and $2.478 \AA$, respectively, Table 2). However, dianion 3 turns out to be a second order transition state (TS) that is not of any chemical relevance. It is telling to compare for $\mathbf{1}$ and $\mathbf{2}$ the $\mathrm{PP}$ bonding interactions. The $\mathrm{PP}$ distance is reduced by just $4 \%$, which is difficult to bring in line with an increase in the binding energy from 6.5 to $30.7 \mathrm{kcal} / \mathrm{mol}$ in the case of $\mathbf{2}$. However, if one considers that $\mathrm{R}(\mathrm{PP})$ in $\mathbf{1}$ is just $0.399 \AA$ longer than the single bond in reference molecule $\mathbf{1 1}$, the reduction of the $\mathrm{R}(\mathrm{PP})$ value is $25.6 \%$. 
Moving from 1 to $\mathbf{2}$, the $\mathrm{PF}$ and $\mathrm{PH}$ bond lengths increase from $1.626(\mathbf{1})$ to $1.785 \AA(\mathbf{2})$ and from 1.410 to $1.416 \AA$, respectively. This indicates that the additional electron preferentially enters the $\sigma^{\star}(P F)+\sigma^{\star}(P F) \mathrm{MO}$, which as a P,P bonding MO (Figure 1 ) leads to the shortening of the interaction distance. Of course, the bond length is not related to the binding energy nor the intrinsic PP interaction strength and therefore an analysis of $\mathrm{R}(\mathrm{PP})$ cannot come to a definite conclusion. The local PP stretching force constants obtained at the $\operatorname{CCSD}(\mathrm{T})$ level of theory increase from 0.144 to 0.410 (CASPT2: 0.168 to 0.406$)$ mdyn $/ \AA$ ), which corresponds to a BSO increase from 0.088 to 0.234 (CASPT2: 0.082 to 0.232 ; Table 2), i.e. although the BSO value is still small there is a 2.6 (2.8) fold increase in the intrinsic strength of the P,P interactions of the radical anion. The energy density at the P,P interaction critical point decreases for 2 from -0.113 hartree $/ \AA^{3}$ (1) to -0.158 hartree $/ \AA^{3}$. This indicates stronger covalent than electrostatic character, but significantly differs from a fully developed covalent $\mathrm{PP}$ bond as found for $\mathbf{1 1}$ (-0.482 hartree $\left./ \AA^{3}\right)$ and $\mathbf{1 1}$ (-0.706 hartree $/ \AA^{3}$; all values calculated with CASPT2).

According to our results, adding an electron to the dimer 1 does not lead to a hypervalent phosphorous molecule. Instead, it leads to a new type of pnicogen bonding, which is characterized by extension of the normal bonding mechanism. Pnicogen bonding implies a mutual charge transfer from the lp orbitals to empty $\sigma^{\star}(P F)$-orbitals, which leads to a lowering of the antibonding character of the resulting $b_{u}$-symmetrical HOMO (Figure 1 ). There is positive overlap between the lp-orbital of one monomer via the H-orbital contributions of the other monomer, which suggests some weak H-lp(P) stabilizing interactions (Figure 1). This interaction is complemented by occupying the $\sigma^{\star}(P F)+\sigma^{\star}(P F)$ LUMO $\left(a_{1 g}\right.$ symmetry) of the neutral complex by an additional electron: There is now a PP interaction via the in-phase coefficients of the $a_{1 g}$ LUMO where this interaction leads to a significant increase of the electron density in the intermonomer space as is reflected by the difference density distribution $\Delta \rho(\mathbf{r})=\rho(\mathbf{2}, \mathbf{r})$ $\rho(\mathbf{1}, \mathbf{r})$ (see Figure 1 ). If pnicogen bonding in $\mathbf{1}$ can be described as weak $\operatorname{lp}(\mathrm{P})-\sigma^{\star}(P F)$ interactions, these are augmented in the radical anion by $\sigma^{\star}(P F)+\sigma^{\star}(P F)$ one-electron-six center (1e-6c) delocalization interactions between two $\mathrm{PH}_{2}$ groups. It is justified to speak of superpnicogen bonding considering the 2.8-fold increase in the $\mathrm{BSO}$ value and the positive difference density distribution in the intermonomer region (Figure 1).

The first and second electron affinity (EA) of the monomer 6 both reveal thermodynamic destabilization of the radical anion 7 and the dianion $8(\mathrm{CCSD}(\mathrm{T}): 13.9$ and 75.4 $\mathrm{kcal} / \mathrm{mol}$; CASPT2: 16.3 and $79.4 \mathrm{kcal} / \mathrm{mol}$, Table 1) although they correspond to genuine minima at both levels of theory according to the vibrational frequency calculations (geometries are given in Figure 2). The EA of the radical anion 2 is stabilizing ( $\operatorname{CCSD}(\mathrm{T})$ : 10.1; CASPT2: $7.9 \mathrm{kcal} / \mathrm{mol}$ ) in line with the BDE values of about 30 $\mathrm{kcal} / \mathrm{mol}$.

We also considered the formation of a Rydberg anion in the case of $\mathbf{2}$. The $\mathrm{NH}_{4}{ }^{-}$molecule is a typical example of such an anion.[32, 33] It can be characterized as a $\mathrm{NH}_{4}{ }^{+}$cation that has captured an electron pair in its outer sphere. Hence, a Ryberg anion requires a strongly electronegative central atom and a charge hole. Both requirements are not fulfilled. However, each of the two $\mathrm{P}$ atoms is positively charged because of the $\mathrm{H}$ and $\mathrm{F}$ substituents and the negative charge of the extra electron is preferentially localized in the nonbonding sphere of the monomer including weakly the four $\mathrm{H}$ atoms of the complex. This resembles a Rydberg anion, which is in line with the fact that the $\mathrm{P}, \mathrm{P}$ interactions have not so much increased compared to the increase in the $\Delta E$ (less than 3 fold increase in $\mathrm{PP}$ strength compared to a more than 4.5 fold increase in $\Delta E$ ). These considerations make it desirable to investigate also the nature for the cation and dication of the dimer $\mathbf{1}$.

The radical cation and dication dimers $\left(\mathrm{PH}_{2} \mathrm{~F}\right)_{2}{ }^{\cdot+}$ (4) and $\left(\mathrm{PH}_{2} \mathbf{F}\right)_{2}{ }^{2+}(5)$. The radical cation has been investigated before.[34, 35, 36] Coupled cluster calculations describe the monocation and dication dimers 4 and 5 both as stable local minima. The first ionization requires 8.66 $\mathrm{eV}$, and the second ionization another $12.95 \mathrm{eV}$, i.e. monocation $\mathbf{4}$ and dication $\mathbf{5}$ are 258.2 and $498.3 \mathrm{kcal} / \mathrm{mol}$ less stable than their neutral counterpart (Table 1). Dissociation of 4 requires $64.9 \mathrm{kcal} / \mathrm{mol}$ whereas the homolytic dissociation of $\mathbf{5}$ is endothermic by $24.5 \mathrm{kcal} / \mathrm{mol}(\omega \mathrm{B} 97 \mathrm{XD})$ and DSD-BLYP: 31.3 and $30.8 \mathrm{kcal} / \mathrm{mol}$ this work; 39.4 $\mathrm{kcal} / \mathrm{mol} \mathrm{MP2/CBS[37]).} \mathrm{Heterolytic} \mathrm{dissociation} \mathrm{of} \mathrm{the}$ dication into $\mathrm{PH}_{2} \mathrm{~F}^{2+}$ and neutral $\mathrm{PH}_{2} \mathrm{~F}$ requires 151.7 $\mathrm{kcal} / \mathrm{mol}$.

The dication dimer $\left(\mathrm{PH}_{2} \mathrm{~F}\right)_{2}{ }^{2+}$ has a PP covalent bond close to a normal PP single bond $(\mathrm{R}(\mathbf{5})$ : 2.288; $\mathrm{R}(\mathbf{1 1})$ : $2.238 \AA ; k^{a}$ : 1.710 and $1.769 \mathrm{mdyn} / \AA$; BSO: 0.893 and 0.923 ; Table 2 ). The relative short PP bond length in 5 is clearly the result of no longer occupying a weakly bonding $b_{u}$ orbital and a smaller covalent radius of a positively charge phosphorous. One can speak of a double phosphonium ion that has bonding features similar to those of a phosphonium ion.

Addition of an electron to the dication leads to weakening by $50 \%$ of the bond strength (BSO: 0.450; bond length increases to $2.315 \AA$ ), which indicates increased repulsion involving now three electrons and thus reducing the single bond strength. BSO value and energy density identify the $\mathrm{PP}$ bond in radical cation 4 to be weak and covalent, but not having a pnicogen bonding character. Comparison of the properties of $\mathbf{4}$ and $\mathbf{2}$ suggests that the latter does not represent a Rydberg anion of the former in the sense it was found for the pair $\mathrm{NH}_{4}{ }^{+} / \mathrm{NH}_{4}{ }^{-} \cdot[32,33]$

We note that the radical anion of the monomer $(\mathbf{7})$ and the corresponding dianion $\mathbf{8}$ are located at global minima, but are thermodynamically unstable. Their charge distribution indicates that the extra electron is predominantly located at $\mathrm{F}$ and he $\mathrm{H}$ atoms. In connection with rad- 
ical cation 9 it is worth to be mentioned that this dissociates first to the donor acceptor complex $\mathrm{PF}^{+\cdot} \cdots \mathrm{H}_{2}$ $(28.1 \mathrm{kcal} / \mathrm{mol})$ before it dissociates in a second step to $P F^{+\cdot}+H_{2}(11.1 \mathrm{kcal} / \mathrm{mol}, \mathrm{CCSD}(\mathrm{T}))$.

\section{Conclusions}

In this work, we have shown that pnicogen bonding in the dimer of $\mathrm{PH}_{2} \mathrm{~F}$ can be enhanced by electron attachment leading to the radical anion dimer $\mathbf{2}$ with a singly occupied HOMO of PP bonding character. The radical anion $\mathbf{2}$ has a significant stronger PP interaction as is revealed by a BSO increase from 0.088 to 0.234 and a binding energy of $30.4 \mathrm{kcal} / \mathrm{mol}$. Local stretching force constant, the positive difference electron density in the intermonomer region, and the increased stabilizing energy density between the $\mathrm{P}$ atoms justify to characterize the $\mathrm{PP}$ interactions by the term super-pnicogen bonding.

Occupation of the HOMO of $\mathbf{2}$ by a second electron leads to a chemically irrelevant second order TS. The radical cation 4 and dication 5 of the dimer of $\mathrm{PH}_{2} \mathrm{~F}$ possess weak or normal covalent $\mathrm{PP}$ bonding typical of a 3e-bonded phosphonium-phosphine adduct or a 2e-bonded diphosphonium ion, respectively. We can exclude that the radical anion $\mathbf{2}$ contains hypervalent $\mathrm{P}$ or is a Rydberg anion corresponding to a complex between the radical cation 4 and an electron pair.

The findings of this work suggest the existence of a whole group of anionic super-pnicogen bonded complexes involving amines, phosphines, arsines, stibines, and bismuthines.

\section{Acknowledgement}

This work was financially supported by the National Science Foundation, Grants CHE 1152357 and CHE 1464906. We thank SMU for providing computational resources.

[1] W. E. Hill, L. M. Silva-Trivino, Preparation and Characterization of Di(tertiary phosphines) with Electronegative Substituents. 1. Symmetrical Derivatives, Inorg. Chem. 17 (1978) 2495-2498.

[2] S. Zahn, R. Frank, E. Hey-Hawkins, B. Kirchner, Pnicogen Bonds: A New Molecular Linker?, Chem. Eur. J. 17 (2011) 6034-6038.

[3] A. Bauzá, D. Quinonero, P. M. Deyá, A. Frontera, Halogen Bonding versus Chalchogen and Pnicogen Bonding: Combined Cambridge Structural Database and Theoretical Study, Cryst. Eng. Comm. 15 (2013) 3137-3144.

[4] D. Setiawan, E. Kraka, D. Cremer, Description of Pnicogen Bonding with the Help of Vibrational Spectroscopy - The Missing Link Between Theory and Experiment, Chem. Phys. Lett. 614 (2014) 136-142.

[5] D. Setiawan, E. Kraka, D. Cremer, Strength of the Pnicogen Bond in Complexes Involving Group 5A Elements N, P, and As, J. Phys. Chem. A 119 (2014) 1642-1656.

[6] J. E. Del Bene, I. Alkorta, J. Elguero, The Pnicogen Bond in Review: Structures, Binding Energies, Bonding Properties, and Spin-Spin Coupling Constants of Complexes Stabilized by Pnicogen Bonds, in: Noncovalent Forces, Springer, 2015, pp. $191-263$.
[7] C. Wang, L. Guan, D. Danovich, S. Shaik, Y. Mo, The Origins of the Directionality of Noncovalent Intermolecular Interactions, J. Comput. Chem.

[8] D. Cremer, E. Kraka, Chemical Bonds without Bonding Electron Density - Does the Difference Electron Density Analysis Suffice for a Description of the Chemical Bond?, Angew. Chem. Int. Ed. Engl. 23 (1984) 627.

[9] D. Cremer, E. Kraka, A Description of the Chemical Bond in Terms of Local Properties of Electron Density and Energy, Croat. Chem. Acta 57 (1984) 1259.

[10] E. Kraka, D. Cremer, Chemical Implication of Local Features of the Electron Density Distribution, in: Z. Maksic (Ed.), Theoretical Models of Chemical Bonding. The Concept of the Chemical Bond, Vol 2, Springer Verlag, Heidelberg, Germany, 1990, p. 453.

[11] Z. Konkoli, D. Cremer, A New Way of Analyzing Vibrational Spectra I. Derivation of Adiabatic Internal Modes, Int. J. Quant. Chem. 67 (1998) 1.

[12] D. Cremer, E. Kraka, From Molecular Vibrations to Bonding, Chemical Reactions, and Reaction Mechanism, Curr. Org. Chem. 14 (2010) 1524-1560.

[13] W. Zou, R. Kalescky, E. Kraka, D. Cremer, Relating Normal Vibrational Modes To Local Vibrational Modes With The Help of an Adiabatic Connection Scheme, J. Chem. Phys. 137 (2012) 084114.

[14] J.-D. Chai, M. Head-Gordon, Long-range Corrected Hybrid Density Functionals with Damped Atom-Atom Dispersion Corrections, Phys. Chem. Chem. Phys. 10 (2008) 6615-6620.

[15] J.-D. Chai, M. Head-Gordon, Systematic Optimization of LongRange Corrected Hybrid Density Functionals, J. Chem. Phys. 128 (2008) 084106-15.

[16] S. Kozuch, D. Gruzman, J. M. Martin, DSD-BLYP: A General Purpose Double Hybrid Density Functional Including Spin Component Scaling and Dispersion Correction, J. Phys. Chem. C 114 (48) (2010) 20801-20808.

[17] K. Raghavachari, G. W. Trucks, J. A. Pople, M. Head-Gordon, A Fifth-order Perturbation Comparison of Electron Correlation Theories, Chem. Phys. Lett. 157 (1989) 479.

[18] K. Andersson, P. A. Malmqvist, B. O. Roos, A. J. Sadlej, K. Wolinski, Second-Order Perturbation Theory with a CASSCF Reference Function, J. Phys. Chem. 94 (14) (1990) $5483-5488$.

[19] T. Dunning, Gaussian Basis Sets for Use in Correlated Molecular Calculations. I. The Atoms Boron Through Neon and Hydrogen, J. Chem. Phys 90 (1989) 1007-1023.

[20] D. Woon, T. Dunning, Gaussian Basis Sets for Use in Correlated Molecular Calculations. III. The Atoms Aluminum Through Argon, J. Chem. Phys 98 (1993) 1358-1371.

[21] S. Boys, F. Bernardi, The Calculation of Small Molecular Interactions by The Differences of Separate Total Energies. Some Procedures with Reduced Errors, Mol. Phys. 19 (1970) 553-566.

[22] K. A. Peterson, T. H. Dunning Jr., Accurate Correlation Consistent Basis Sets for Molecular Core-valence Correlation Effects: The Second Row Atoms Al-Ar, and the First Row Atoms B-Ne Revisited, J. Chem. Phys. 117 (2002) 10548-10560.

[23] J. L. Sonnenberg, H. B. Schlegel, H. P. Hratchian, Spin Contamination in Inorganic Chemistry Calculations, in: E. I. Solomon, R. A. Scott, R. B. King (Eds.), Computational Inorganic and Bioinorganic Chemistry, John Wiley \& Sons, New York, 1990, pp. $1-13$.

[24] Y. He, D. Cremer, Spin-projected Coupled-cluster Theory with Single and Double Excitations, Theor. Chem. Acc. 105 (2000) 132-144.

[25] D. Cremer, J. Gauss, Theoretical Determination of Molecular Structure and Conformation. 20. Re-evaluation of the Strain Energies of Cyclopropane and Cyclobutane - $\mathrm{CC}$ and $\mathrm{CH}$ Bond Energies, 1,3-Interactions, and $\sigma$-Aromaticity, J. Am. Chem. Soc. 108 (1986) 7467-7477.

[26] W. Zou, D. Cremer, $C_{2}$ in a Box: Determining its Intrinsic Bond Strength for the $X^{1} \Sigma_{g}^{+}$Ground State, Chem. Eur. J. 22 (2016) 4087-4089. 
[27] E. Kraka, W. Zou, M. Filatov, J. Gräfenstein, D. Izotov, J. Gauss, Y. He, A. Wu, V. Polo, L. Olsson, Z. Konkoli, Z. He, D. Cremer, COLOGNE16 (2016).

[28] H. J. Werner, P. J. Knowles, G. Kniza, F. R. Manby, M. Schütz, other, MOLPRO, version 2010.1, A Package of Ab Initio Programs, see http//www.molpro.net (2010).

[29] J. F. Stanton, J. Gauss, M. E. Harding, P. G. Szalay, et.al., CFOUR, see http//www. cfour.de (2010).

[30] T. Keith, TK Gristmill Software (aim.tkgristmill.com, Overland Park KS, USA (2011).

[31] J. V. Coe, J. T. Snodgrass, C. B. Freidhoff, K. M. McHugh, K. H. Bowen, Negative Ion Photoelectron Spectroscopy of the Hydride-ammonia Negative Cluster Ion H-( $\left.\mathrm{NH}_{3}\right)_{1}$, J. Chem. Phys. 83 (1985) 3169-3170.

[32] D. Cremer, E. Kraka, Theoretical Determination of Molecular Structure and Conformation. 17. On the Existence of $\mathrm{FH}_{2}^{-}$, $\mathrm{OH}_{3}^{-}, \mathrm{NH}_{4}^{-}$, and $\mathrm{CH}_{5}^{-}$in the Gas Phase,, J. Phys. Chem. 90 (1986) 33-40.

[33] J. D. Wadey, N. A. Besley, The Structure and Bonding of Mixed Component Radical Cation Clusters, Chem. Phys. Lett. 601 (2014) $110-115$

[34] L. F. Ji, A. J. Li, Z. Z. Li, Structures and Stabilities of Hemibonded vs Proton-transferred Isomers of Dimer Radical Cation Systems $\left(\mathrm{XH}_{3}-\mathrm{YH}_{3}\right)^{(+)}(\mathrm{X}, \mathrm{Y}=\mathrm{N}, \mathrm{P}, \mathrm{As})$, Chem. Phys. Lett. 619 (2015) 115-121.

[35] L. F. Ji, A. J. Li, Z. Z. Li, Z. X. Ge, Substituent Effects on the Properties of the Hemi-bonded Complexes $\left(\mathrm{XH}_{2} \mathrm{P} \cdots \mathrm{NH}_{2} \mathrm{Y}\right)^{+}$ (X, Y=H, F, Cl, Br, $\mathrm{NH}_{2}, \mathrm{CH}_{3}, \mathrm{OH}$ ), J. Mol. Model. 22 (2016) 1 .

[36] M. Marin-Luna, I. Alkorta, J. Elguero, A Computational Study on $\left[\left(\mathrm{PH}_{2} \mathrm{X}\right)_{2}\right] \cdot+$ Homodimers Involving Intermolecular Twocenter Three-electron Bonds, Structural Chemistry (2015) 1-10. 


\begin{tabular}{|c|c|c|c|}
\hline \# & $\begin{array}{l}\text { Molecule } \\
\text { Dimer }\end{array}$ & $\operatorname{CCSD}(\mathrm{T})$ & CASPT2 \\
\hline \multicolumn{4}{|c|}{ Binding Energy } \\
\hline 1 & $\left(\mathrm{PH}_{2} \mathrm{~F}\right)_{2}$ & 6.41 & 6.50 \\
\hline 2 & $\left(\mathrm{PH}_{2} \mathrm{~F}\right)_{2} \cdot-$ & 30.39 & 30.73 \\
\hline \multirow[t]{2}{*}{3} & $\left(\mathrm{PH}_{2} \mathrm{~F}\right)_{2}{ }^{2-b}$ & -28.69 & -28.04 \\
\hline & heterolytic & 35.10 & \\
\hline 4 & $\left(\mathrm{PH}_{2} \mathrm{~F}\right)_{2} \cdot+$ & 64.93 & \\
\hline 5 & $\left(\mathrm{PH}_{2} \mathrm{~F}\right)_{2}{ }^{2+}$ & 24.50 & \\
\hline \multicolumn{4}{|c|}{ Electron Affinity } \\
\hline 1 & $\left(\mathrm{PH}_{2} \mathrm{~F}\right)_{2}$ & -10.09 & -7.95 \\
\hline 2 & $\left(\mathrm{PH}_{2} \mathrm{~F}\right)_{2} \cdot-$ & 72.98 & 75.05 \\
\hline 6 & $\mathrm{PH}_{2} \mathrm{~F}$ & 13.89 & 16.28 \\
\hline 7 & $\mathrm{PH}_{2} \mathrm{~F}^{--}$ & 75.44 & 79.38 \\
\hline \multicolumn{4}{|c|}{ Ionization Potential } \\
\hline 1 & $\left(\mathrm{PH}_{2} \mathrm{~F}\right)_{2}$ & 199.69 & \\
\hline 4 & $\left(\mathrm{PH}_{2} \mathrm{~F}\right)_{2}+$ & 298.63 & \\
\hline 6 & $\mathrm{PH}_{2} \mathrm{~F}$ & 258.20 & \\
\hline 9 & $\mathrm{PH}_{2} \mathrm{~F}^{\cdot+}$ & 385.41 & \\
\hline
\end{tabular}

Table 1: Binding energies, diabatic electron affinities, and diabatic ionization potentials of monomers and dimers $\mathbf{1}$ - 9 calculated at the $\operatorname{CCSD}(\mathrm{T})$ or $\operatorname{CAS}(\mathrm{N}, 8) \mathrm{PT} 2 /$ aug-cc-pVTZ level; $(\mathrm{N}=4-6)$ levels of theory.

\begin{tabular}{|c|c|c|c|c|c|c|c|c|c|}
\hline \multirow{2}{*}{ No. } & \multirow{2}{*}{$\begin{array}{l}\text { Molecule, } \\
\text { Complex }\end{array}$} & \multicolumn{4}{|c|}{$\operatorname{CCSD}(\mathrm{T})$} & \multicolumn{4}{|c|}{ CASPT2 } \\
\hline & & $\begin{array}{c}R(P P) \\
\AA\end{array}$ & $\begin{array}{l}k^{a}(P P) \\
\operatorname{mdyn} / \AA\end{array}$ & $\begin{array}{c}w^{a}(P P) \\
\mathrm{cm}^{-1}\end{array}$ & $n(P P)$ & $\begin{array}{c}R(P P) \\
\AA\end{array}$ & $\begin{array}{l}k^{a}(P P) \\
\operatorname{mdyn} / \AA\end{array}$ & $\begin{array}{c}\omega^{a}(P P) \\
\mathrm{cm}^{-1}\end{array}$ & $n(P P)$ \\
\hline 1 & $\left(\mathrm{PH}_{2} \mathrm{~F}\right)_{2}$ & 2.628 & 0.144 & 125.8 & 0.088 & 2.618 & 0.168 & 104.8 & 0.082 \\
\hline 2 & $\left(\mathrm{PH}_{2} \mathrm{~F}\right)_{2} \cdot-$ & 2.541 & 0.410 & 212.0 & 0.234 & 2.514 & 0.466 & 174.4 & 0.232 \\
\hline 3 & $\left(\mathrm{PH}_{2} \mathrm{~F}\right)_{2}{ }^{2-}$ & 2.478 & 0.463 & 225.4 & 0.262 & 2.488 & 0.585 & 195.5 & 0.292 \\
\hline 4 & $\left(\mathrm{PH}_{2} \mathrm{~F}\right)_{2}^{\cdot+}$ & 2.315 & 0.824 & 300.5 & 0.450 & & & & \\
\hline 5 & $\left(\mathrm{PH}_{2} \mathrm{~F}\right)_{2}{ }^{2+}$ & 2.288 & 1.710 & 432.9 & 0.893 & & & & \\
\hline 11 & $\mathrm{P}_{2} \mathrm{H}_{4}$ & 2.238 & 1.769 & 440.3 & 0.923 & 2.217 & 1.872 & 452.9 & 0.951 \\
\hline 12 & $\mathrm{P}_{2} \mathrm{H}_{2}$ & 2.051 & 3.334 & 604.4 & 1.673 & 2.041 & 3.327 & 603.8 & 1.705 \\
\hline
\end{tabular}

Table 2: Characterization of the $P, P$ interaction in neutral and ionic dimers of $\mathrm{PH}_{2} \mathrm{~F}$ by distance $R$, local stretching force constants $k^{a}$,local stretching frequency $\omega^{a}$, and relative bond strength order (BSO) $n .^{a}$ 


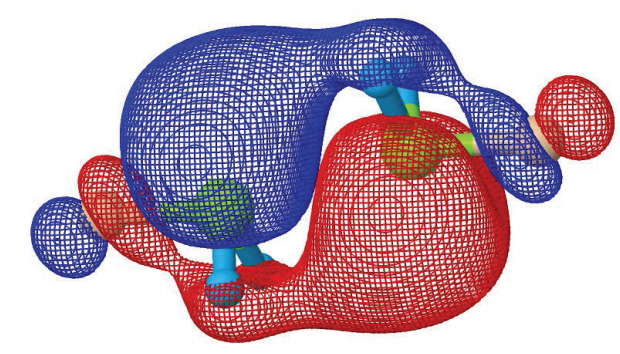

(a) $\mathrm{HOMO}\left(B_{u}\right),\left(\mathrm{PH}_{2} \mathrm{~F}\right)_{2}$

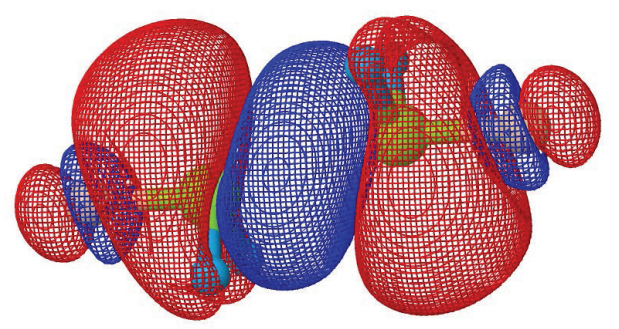

(b) LUMO $\left(A_{g}\right),\left(\mathrm{PH}_{2} \mathrm{~F}\right)_{2}$

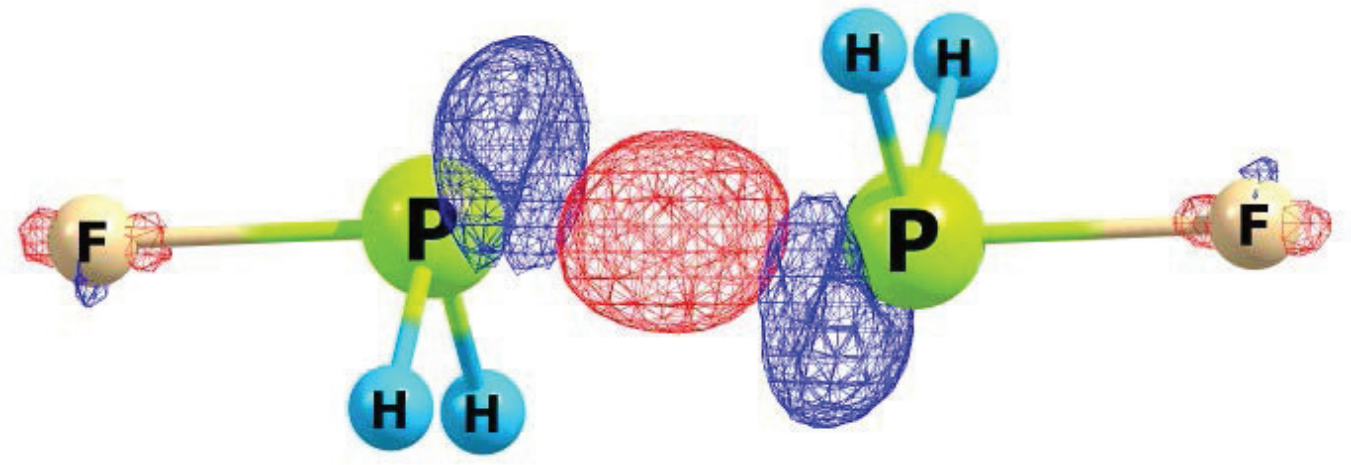

(c) Difference electron density, $\left(\mathrm{PH}_{2} \mathrm{~F}\right)_{2} \cdot-$

Figure 1: a) and b): Frontier natural orbitals of the $\mathrm{PH}_{2} \mathrm{~F}$ dimer $\mathbf{1}$ calculated at the CAS(4,8)PT2/aug-cc-pVTZ level of theory. $\left.\mathbf{c}\right)$ Perspective drawing of the difference electron density distribution $\Delta \rho(\mathbf{r})=\rho(\mathbf{2}, \mathbf{r})-\rho(\mathbf{1}, \mathbf{r})$ calculated for the 0.002 a.u. electron density surface (red/blue contour lines denote positive/negative difference electron density). 
(1.410)

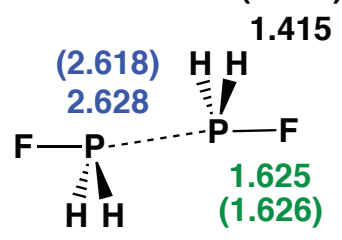

$\mathrm{PPF}=165.1 \quad \mathrm{HPH}=95.2(95.4)$

$\mathrm{HPF}=98.3(98.2) \quad \mathrm{FPPF}=180.0$

$$
1, \mathrm{C}_{2 \mathrm{~h}}
$$

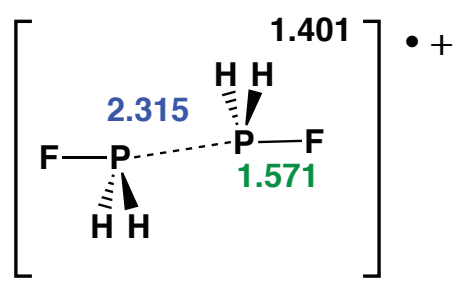

PPF $=139.4 \quad \mathrm{HPH}=106.4$

$\mathrm{HPF}=103.8 \quad \mathrm{FPPF}=180.0$

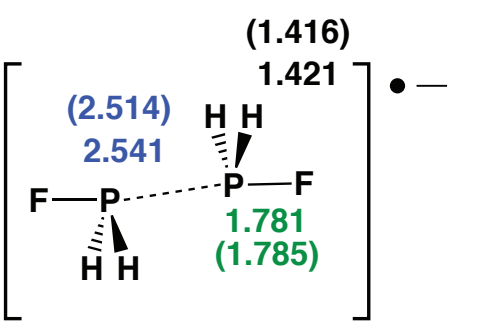

$\mathrm{PPF}=176.4(177.2)$

$\mathrm{HPH}=96.4$ (96.5)

$\mathrm{FPPF}=180.0$

$$
2, \mathrm{C}_{2 \mathrm{~h}}
$$

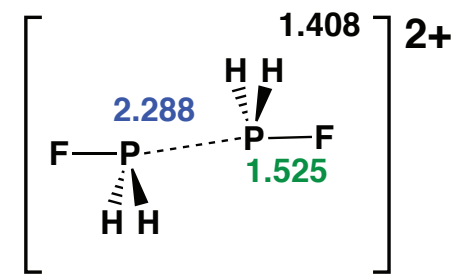

$\mathrm{PPF}=104.5 \quad \mathrm{HPH}=113.6$

$\mathrm{HPF}=110.7 \quad \mathrm{FPPF}=180.0$

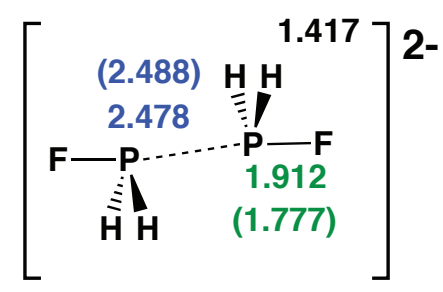

PPF $=176.5(170.8)$

$\mathrm{HPF}=89.9$ (85.2)

$$
3, \mathrm{C}_{2 \mathrm{~h}}
$$

$\mathrm{HPH}=96.3(98.0)$

1.622

${ }_{F}^{(1.623)}-P_{H}^{P_{* i / / / H}} \begin{gathered}1.423 \\ (\mathbf{1 . 4 1 6})\end{gathered}$

$\mathrm{HPF}=97.6$

$\mathrm{HPH}=92.1(92.3)$

\section{$4, C_{2 h}$}

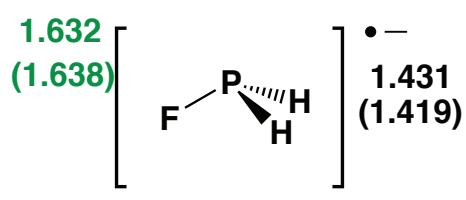

$$
\mathrm{HPF}=97.6(97.9)
$$

$\mathrm{HPH}=92.5(92.6)$

$$
7, \mathrm{C}_{\mathrm{s}}
$$

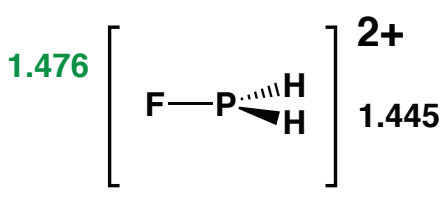

$$
\begin{aligned}
& \mathrm{HPF}=114.7 \\
& \mathrm{HPH}=130.5
\end{aligned}
$$

$10, C_{s}$
$5, C_{2 h}$

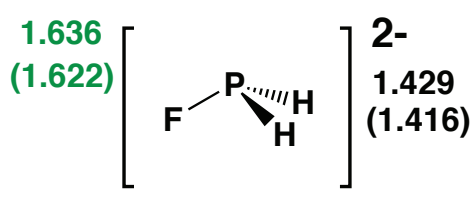

$\mathrm{HPF}=97.3(97.8)$

$\mathrm{HPH}=94.2(94.3)$

8, $\mathrm{C}_{\mathrm{s}}$

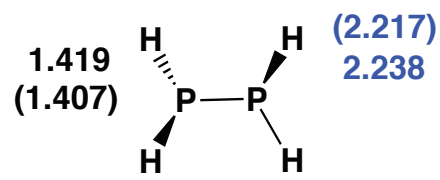

$\mathrm{PPH}_{\mathrm{i}}=94.4$ (94.2)

$\mathrm{PPH}_{\mathrm{O}}=99.2$ (99.7)

$\mathrm{H}_{0} \mathrm{PH}_{\mathrm{i}}=93.9(94.2)$

$\mathrm{H}_{\mathrm{PPPH}}=173.4(173.1)$
$\mathrm{H}_{\mathrm{o}} \mathrm{PPH}_{\mathrm{o}}=17.1(17.0)$

$11, C_{2}$

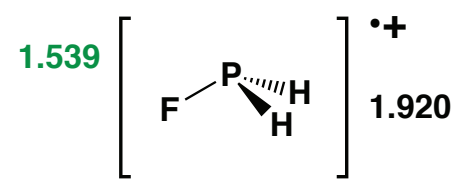

$\mathrm{HPF}=92.4 \quad \mathrm{HPH}=23.8$

$9, \mathrm{C}_{\mathrm{s}}$

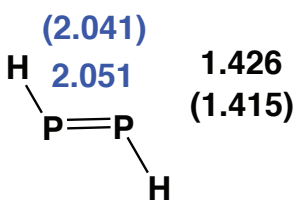

$\mathrm{PPH}=93.9$ (93.6)

$\mathrm{HPPH}=180.0$

12, $C_{2 h}$

Figure 2: Optimized geometries of monomers and dimers 1 - 12 obtained at the CCSD(T) and CASPT2 (in parentheses) levels of theory using aug-cc-pVTZ basis sets. Bond lengths PP (blue), PF (green), and PH (black) are given in $\AA$. Bond angles and dihedrals are in degree. Dianion $\mathbf{3}$ is a second order transition state. The reference molecules $\mathbf{1 1}$ and $\mathbf{1 2}$ are also included. 


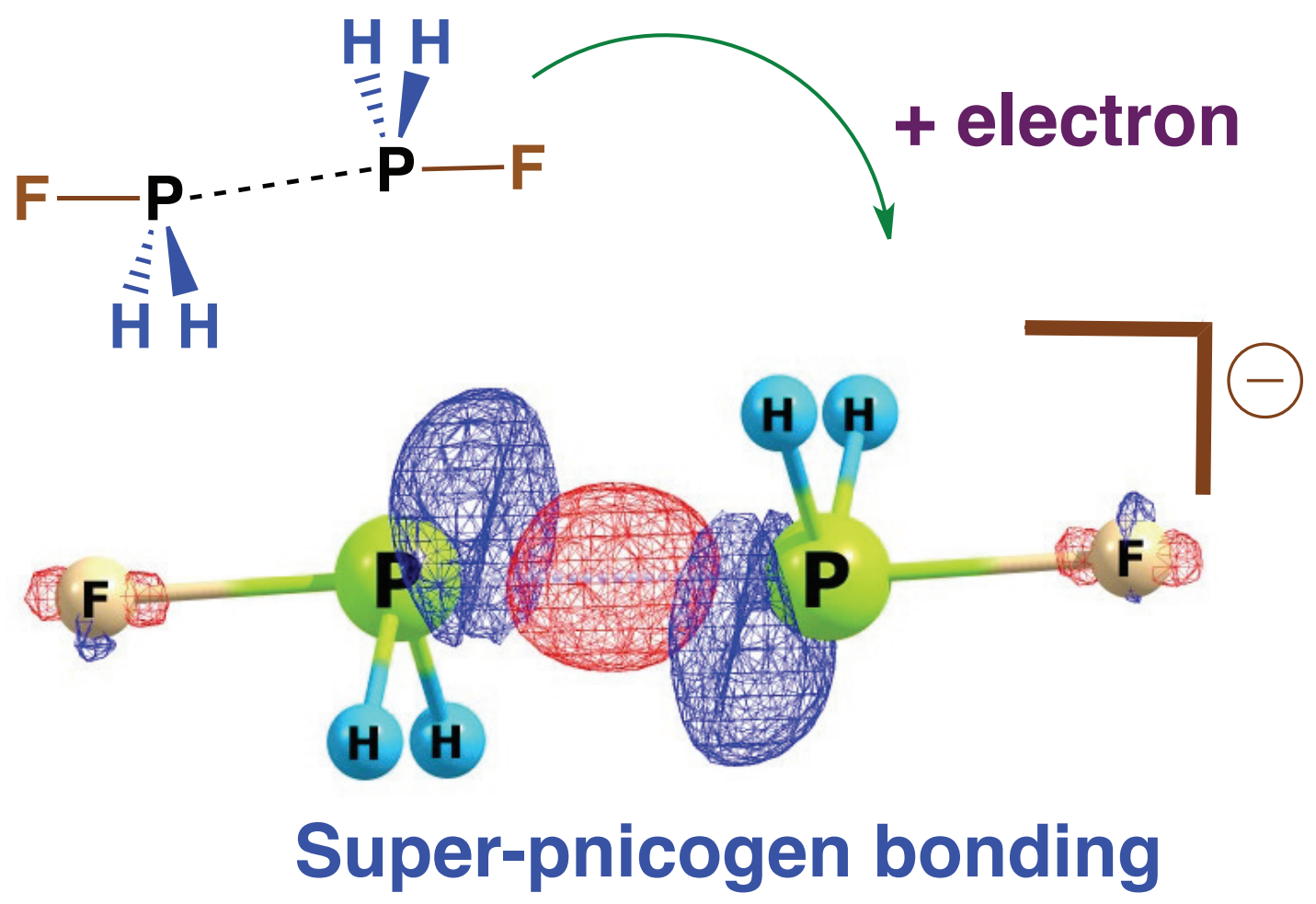

Figure 3: Table of Contents (TOC) 